\title{
INFLUENCIA DEL ESTADO DE ÁNIMO SOBRE LA SUPRESIÓN DE IMÁGENES
}

\author{
GEMMA GARCÍA y AMPARO BELLOCH
}

\author{
Universidad de Valencia
}

(Aceptado en febrero de 2004)

\begin{abstract}
El objetivo de este trabajo ha sido estudiar cómo influye el estado de ánimo negativo (EA) sobre la supresión de imágenes negativas, congruentes con ese EA. Sesenta y dos sujetos sin patología participaron en el experimento que constó de dos partes: (1) inducción de EA triste, y (2) supresión. Este último estuvo formado a su vez por tres partes en las que se midió la frecuencia de intrusiones de la imagen objetivo (línea base, instrucción experimental supresión vs. control, y registro). Todos los sujetos fueron asignados de forma aleatoria a cuatro grupos: no inducción, no supresion; no inducción, supresión; inducción, no supresión e inducción, supresión. Los resultados muestran que en ninguno de los grupos experimentales se produjo un aumento inmediato ni demorado en la frecuencia de la imagen objetivo, y que los grupos, independientemente de la condición experimental mostraron un comportamiento similar en todas las variables evaluadas.
\end{abstract}

Palabras clave: imágenes intrusas, intrusiones, inducción de estado de ánimo, supresión, trastorno obsesivo compulsivo, depresión.

\section{Influence of the mood state on the suppression of images}

The aim of this paper has been to study the influence of an induced negative mood state on the suppression of mood-congruent negative images. Sixty-two nonclinical subjects participated in the experiment which had two parts: (1) mood induction and (2) thought suppression experiment. In the suppression experiment, the subjects were instructed to report along three periods (base-line monitoring, experimental instruction suppress vs. monitor, and monitoring) the occurrences of a "negative image», previously presented $(5 \mathrm{~m}$.). Subjects were randomly assigned to four groups: non induction, non suppression; non induction, suppression; induction, non suppression; and induction, suppression. The results revealed neither immediate nor delayed frequency increases in the target image, and the response pattern to all the variables assessed (frequency of intrusions, subjective success after suppression efforts, discomfort by the intrusions) was equivalent in all subjects, irrespective of the experimental condition in which they were ascribed.

Key words: intrusive images, intrusions, mood state induction, suppression, obsessive-compulsive disorder, depressive disorder.

\section{INTRODUCCIÓN}

Desde los modelos cognitivo-conductuales del TOC (Purdon y Clark, 1999; Rachman, 1997, 1998, 2002; Salkovskis, 1985, 1989) se considera que las obsesiones clínicas

Correspondencia: Gemma García Soriano, Departamento de Personalidad, Evaluación y Tratamientos Psicológicos, Facultad de Psicologia, Universidad de Valencia, Avda. Blasco Ibáñez 21, 46010 Valencia. Correo-e: Gemma.Garcia@uv.es tienen su origen en determinados pensamientos intrusos (PI) que experimentan los sujetos carentes de psicopatología, siendo

Agradecimientos: La investigación que da origen a este trabajo se ha realizado gracias a una Beca predoctoral del programa nacional de Formación de Profesorado Universitario (FPU) concedida por el Ministerio de Educación y Ciencia a la primera autora (AP20032630), y forma parte del proyecto de investigación BSO2002-02330 aprobado y financiado por el Ministerio de Ciencia y Tecnología con participación de fondos FEDER. 
el significado o interpretación que el sujeto da a sus PI, el primer paso para que se conviertan en obsesiones. Estas valoraciones activan intentos por controlar o suprimir tales PI, que suelen ser infructuosos y contribuyen al mantenimiento y/o exacerbación de las obsesiones. El modelo de Clark y Purdon (1993; Purdon y Clark, 1999,2000 ) es el que proporciona una mayor atención a la supresión de las obsesiones en la explicación del TOC.

En los últimos 15 años, y a partir del trabajo de Wegner, Schneider, Carter y White (1987), se ha desarrollado una línea de investigación experimental encaminada a poner a prueba los efectos de la supresión del pensamiento en un contexto de laboratorio. El interés se sitúa en la observación de dos tipos de efectos, consecuentes a los esfuerzos activos de supresión: (1) aumento inmediato del pensamiento, y (2) aumento demorado. En el primer caso, los esfuerzos de supresión están todavía en marcha, mientras que en el segundo la persona ya ha cesado en tales esfuerzos, razón por la cual la reaparición de intrusiones se denomina también «efecto rebote». Wegner (1994) desarrolló un modelo teórico sobre los efectos paradójicos del auto-control mental, que permite explicar por qué en ocasiones muchas de las tareas relacionadas con el mismo (p.ej., suprimir un pensamiento, concentrarse en una tarea, dormirse, cambiar un estado de ánimo...) producen efectos contrarios a los esperados. Respecto a la explicación específica de los efectos paradójicos en la supresión, señalaba que en los intentos de supresión intervienen dos procesos relacionados que funcionan simultáneamente. Un «proceso operativo intencional» que realiza una búsqueda consciente y controlada de pensamientos distractores para poder reemplazar el pensamiento-objetivo; y un "proceso de supervisión paradójica», inconsciente y automático, que rastrea los fallos en la supresión buscando posibles indicios del pensamiento-objetivo. Estos efectos paradójicos de dan especialmente bajo una serie de variables o condiciones como las demandas atencionales, el afecto negativo, o la intención básica de controlar por parte del sujeto.

Las últimas revisiones publicadas de estudios experimentales sobre la supresión de pensamientos (p.ej., Abramowitz, Tolin y Street, 2001; Purdon, 1999; Purdon y Clark, 2000; Rassin, Merckelbach y Muris, 2000), así como los trabajos experimentales que siguen apareciendo sobre este tema (p.ej., Belloch y Morillo, 2002; Belloch, Morillo y Jiménez, 2004; Purdon, 2004) coinciden en señalar las inconsistencias de resultados obtenidas por los diferentes trabajos. Mientras que unos encuentran únicamente efecto inmediato, otros encuentran efecto rebote, $y$ otros no encuentran ningún efecto. Purdon (2004) apunta como explicación de estas inconsistencias las diferencias metodológicas entre los estudios, y otros autores coinciden en la importancia del tipo de pensamiento objetivo (neutro, o emocional y personalmente relevante), siendo la supresión en este último caso, más complicada (McNally y Ricciardi, 1996; Purdon y Clark, 2001). Se ha propuesto (Purdon y Clark, 2000; Rassin, Merckelbach, y Muris, 2000) que la supresión de pensamientos neutros, tal vez sea una línea de trabajo poco útil para la comprensión del TOC. Desde este punto de vista, con el que estamos de acuerdo, el elemento fundamental de investigación es averiguar qué efectos produce, en personas normales, la supresión de los PI. La mayor parte de los estudios dentro de este ámbito (Belloch y Morillo, 2002; Belloch, et al., 2004; Janeck y Calamari, 1999; McNally y Ricciardi, 1996; Purdon y Clark, 2001; Rutledge, 1998; Salkovskis y Campbell, 1994; Trinder y Salkovskis, 1994), coinciden en concluir que los intentos activos para suprimir PI provocan, en una peque- 
ña proporción de sujetos, un efecto rebote (aumento demorado) de esos PI, y en la mayoría de los casos, una ausencia de habituación a los mismos que no se produce cuando los individuos no se involucran en intentos activos de supresión .

Otro de los aspectos que caracteriza al TOC es su elevada comorbilidad con trastornos del Eje I y II, siendo uno de los cuadros comórbidos más comunes la depresión mayor (Yaryura-Tobías, Todazo, Grunes, McKay, Stockman y Nexiroglu, 1996). Se cuenta además con cierta evidencia que sugiere el solapamiento de los sustratos biológicos de ambas condiciones (Insem, Gillin, Moore, Mendelson, Lavenstein y Murphy, 1982).

El estado de ánimo negativo característico de la depresión es conceptuado por Wegner (1994) en términos de carga cognitiva: su presencia disminuye la capacidad mental disponible para ejercer control mental voluntario sobre la actividad cognitiva. Desde los modelos cognitivoconductuales del TOC (Freeston y Ladouceur, 1997; Freeston, Ladouceur, Provencher, y Blais, 1995; Purdon y Clark, 1999; Rachman, 1997, 1998, 2002; Salkovskis, 1985,1989 ), se plantea además que el EA negativo favorece la aparición y/o el mantenimiento de PI negativos e indeseados. Estos planteamientos están a su vez ligados con las investigaciones que se centran en el estudio de la relación entre el EA y la memoria, que se ha realizado desde diferentes perspectivas teóricas (Anderson y Bower, 1973; Bower, 1981; Ingram, 1984; Teaslade y Russell, 1983). En general, se supone que el EA producirá sesgos que favorecerán la percepción de información congruente con ese EA, o bien que influirá sobre la capacidad atencional y los recursos cognitivos disponibles.

Uno de los fenómenos más estudiados ha sido el de la congruencia de la memoria con el EA: la valencia afectiva del material, determina la facilidad con la que posteriormente será almacenado o recordado. Blaney (1986) en un trabajo ya clásico de revisión concluyó que la congruencia del EA era un fenómeno robusto, constatándose a lo largo de diferentes muestras, tareas cognitivas y empleando gran diversidad de material estimular. No obstante, este efecto se ha encontrado en la mayoría de las ocasiones con EA positivos, y no con negativos, y todavía menos en sujetos con depresión clínica.

Esta línea de investigación se ha centrado en el recuerdo de material (palabras, historias, imágenes) congruente $\mathrm{y} / \mathrm{o}$ incongruente con el EA, pero hay otros trabajos (p.ej., Howell y Conway, 1992) que han aplicado la hipótesis de la congruencia con el EA a la supresión de pensamientos congruentes. Se parte de la idea de que el EA ejercerá impacto tanto sobre la accesibilidad de los pensamientos intrusos, como sobre la de los distractores, convirtiendo así los pensamientos congruentes con el EA en más difíciles de suprimir que los no congruentes. La influencia que pueda tener el EA sobre la supresión de pensamientos intrusos es un área todavía poco investigada. Se ha estudiado con estados de ánimo "naturales» clínicos (sujetos deprimidos: Wenzlaff, Wegner y Roper, 1988) y subclínicos (estudiantes con ánimo disfórico: Conway, Howell y Giannopoulos, 1991), y con EA inducidos (Howell y Conway, 1992), siendo el procedimiento de inducción de Velten (1968) el más empleado. En general, se ha encontrado apoyo a la idea de que los sujetos con EA negativo tienen un mayor número de PI negativos, y mayores dificultades para eliminarlos, bien debido a su dificultad para encontrar distractores negativos, a un incremento en la accesibilidad de los PI debido a su congruencia con el EA, o a la menor eficiencia de sus estrategias distractoras.

Se han postulado dos hipótesis generales que relacionan esta baja eficiencia de la supresión cuando se asocia a un EA disfórico: la hipótesis del esfuerzo cogni- 
tivo, y la de la congruencia del estado de ánimo (Conway et al., 1991; Freeston et al., 1995). Según la primera, el menor éxito en la supresión de pensamientos de los sujetos disfóricos, se debe a que tienen una menor capacidad de procesamiento disponible (Conway et al., 1991; Edwards y Dickerson, 1987; Wegner y Erber, 1992); y desde la segunda se explica la baja eficiencia por la mayor accesibilidad a pensamientos desagradables congruentes con el EA (Sutherland, Newman y Rachman, 1982; Wenzlaff et al., 1988).

Hay publicados algunos estudios de corte correlacional que constatan la presencia de asociaciones significativas entre el EA disfórico y variables tales como una mayor frecuencia de pensamientos negativos (Clark, 1992; Freeston, Ladouceur, Thibodeau y Gagnon, 1992; Niler y Beck, 1989; Reynolds y Salkvoskis, 1991), empeoramiento en la percepción de controlabilidad (Rachman, 1981, 1997, 1998), menor control sobre las intrusiones no deseadas (Conway et al., 1991; Howell y Conway, 1992; Reynolds y Salkovskis, 1991; Sutherland et al., 1982; Wenzlaff, Wegner y Klein, 1991; Wenzlaff et al., 1988), incremento de las valoraciones de culpa, desaprobación, intensidad de las intrusiones y creencias sobre la probabilidad de que el pensamiento pueda hacerse realidad (Freeston et al., 1992; Freeston et al., 1995), y menor eficiencia de las estrategias de control de las intrusiones no deseadas (Freeston et al., 1996; Amir et al., 1997; Freeston y Ladouceur, 1997). Todos estos estudios avalan las evidencias, todavía escasas, procedentes de los estudios experimentales en los que se pone en relación la supresión con el EA.

En general, la revisión realizada apunta a una ausencia de resultados concluyentes. Este trabajo intenta aportar algo de claridad a un campo tan confuso y poco investigado desde el punto de vista experimental como el de la relación entre el control de pensamientos intrusos, frecuencia de las intrusiones, procesos de memoria, y estado de ánimo. Nuestro objetivo general es obtener evidencias experimentales que permitan obtener respuestas a una pregunta que, en nuestra opinión, es relevante para avanzar en el conocimiento de la génesis del TOC y su relación con la depresión: ¿Influye el estado de ánimo deprimido en la eficacia para suprimir pensamientos, imágenes o impulsos, cuyos contenidos sean afectivamente congruentes con ese EA? Teniendo como marco de referencia este interés general, en este trabajo nos planteamos los siguientes objetivos: 1) Analizar si el EA triste provoca un aumento de las recurrencias de una imagen visual afectivamente congruentes con ese EA. 2) Investigar si el EA triste induce aumentos paradójicos (aumento inmediato y aumento demorado) en las re-apariciones de una imagen visual afectivamente congruente con el EA como consecuencia de los intentos activos de suprimir esa imagen. 3) Analizar si los sujetos que intentan suprimir activamente una imagen negativa, independientemente de su EA, experimentan más efectos paradójicos (aumento inmediato y aumento demorado) en las re-apariciones de una imagen visual negativa, que los sujetos que no intentan suprimirla. 4) Examinar si el EA triste se asocia a una disminución del esfuerzo para suprimir, a un menor éxito subjetivo, y a un incremento de la molestia que originan las recurrencias de imágenes visuales afectivamente congruentes con dicho estado. Y 5) Averiguar si las personas que se hallan bajo un EA triste utilizan estrategias diferentes a las que se encuentran en un estado afectivo normal para suprimir recurrencias no deseadas de una imagen visual, cuyo contenido afectivo sea congruente con el EA.

Partimos de la hipótesis de que el estado de ánimo influye sobre los intentos deliberados de suprimir un estímulo visual no agradable, de tal manera que bajo un EA negativo, el éxito en los inten- 
tos por suprimir una imagen visual no agradable (y por tanto, congruente con el estado de ánimo), será menor que cuando el EA sea neutro. Por lo tanto, los sujetos cuyo estado de ánimo sea negativo, en comparación con aquellos que mantengan un EA normal:

a) tendrán una mayor recurrencia de intrusiones relacionadas con la imagen,

b) cuando estén intentando suprimirla, no lo conseguirán (tendrán más recurrencias a pesar de que estén intentando neutralizarla o suprimirla: efecto de incremento inmediato),

c) experimentarán más recurrencias de la imagen aun cuando ya no estén intentando suprimirla (efecto rebote),

d) se esforzarán menos por suprimir imágenes que son congruentes con su EA e) valorarán como escaso su éxito en la supresión,

f) experimentarán una molestia mayor como consecuencia de las re-apariciones de la imagen,

g) utilizarán estrategias diferentes para suprimir la imagen.

Estas mismas hipótesis esperamos que se cumplan en el grupo de supresión sin inducción de EA, pero que sean menos acentuadas que en el grupo de inducción. Es decir, la recurrencia, el efecto de incremento inmediato y demorado, y la molestia, serán mayores en los grupos de supresión que en los de no supresión, y dentro de estos primeros, será mayor en aquellos sujetos que suprimen son un EA negativo inducido. Para poner a prueba estas hipotesis se ha seguido el diseño experimental que se ejemplifica en la Figura 1.

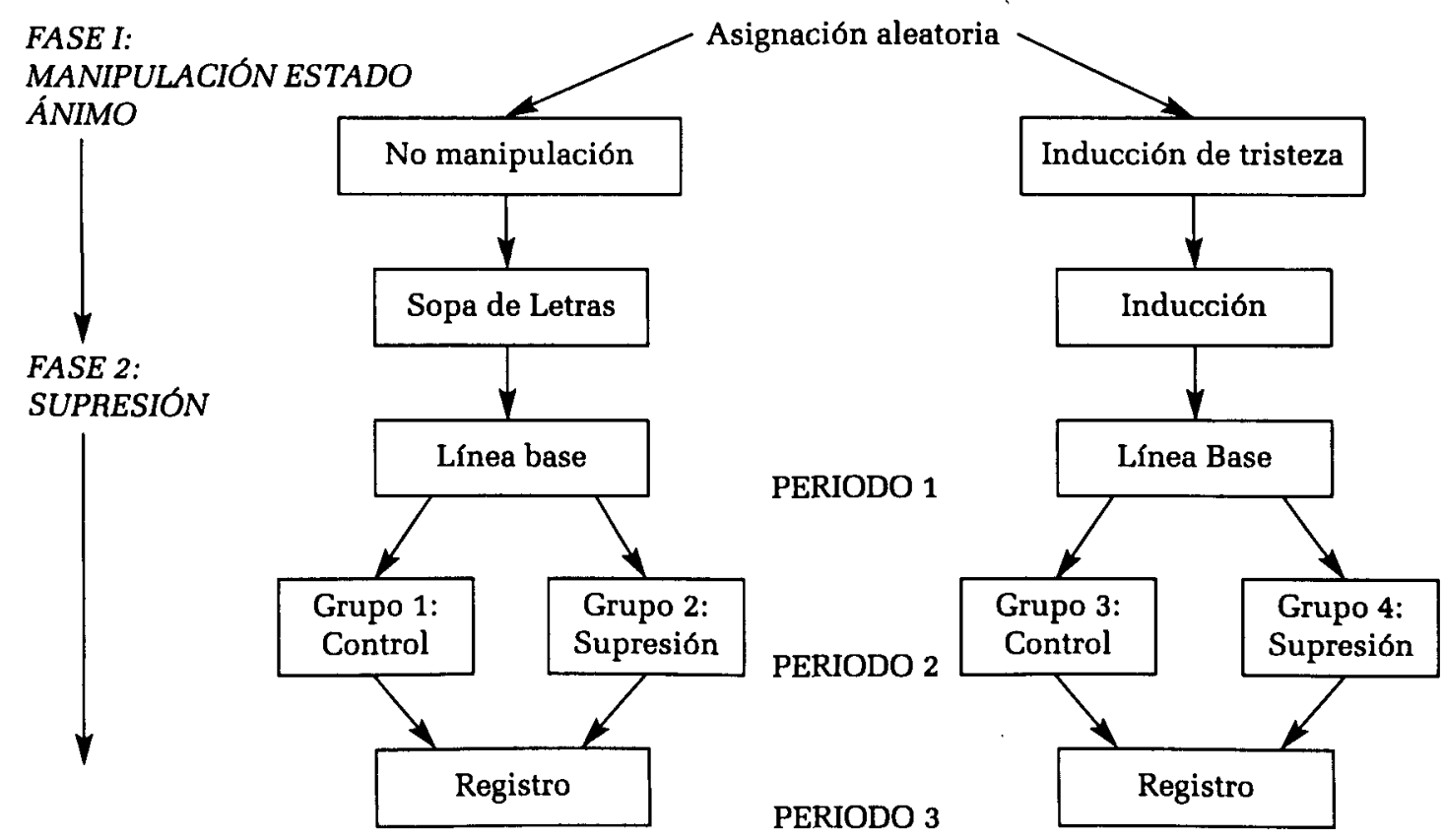

Figura 1. Diseño experimental utilizado en el experimento de inducción de estado de ánimo (EA) triste y supresión de imagen congruente con el EA inducido. El Periodo 1 constituye la línea base (registro de recurrencias de la imagen). El Período 2 permite la constatación de efectos de incremento inmediato de la imagen en los dos grupos de supresión por comparación con sus respectivos grupos control, y entre sí (grupos de supresión) teniendo en cuenta si han recibido o no inducción de estado de ánimo triste. El Período 3 permite constatar la existencia de efecto de incremento demorado (efecto rebote), teniendo en cuenta las mismas condiciones de comparaciones entre grupos que en el Período 2. 


\section{MÉTODO}

\section{Participantes}

Participaron 90 personas (estudiantes universitarios y licenciados) de edades comprendidas entre 18 y 35 años (media \pm 1 DT $=23,50 \pm 4,66$ años). Para la primera fase del experimento (inducción de estado de ánimo triste) se aplicaron dos criterios de exclusión: primero, haber recibido diagnóstico de trastorno mental en el último año (o estar recibiendo tratamiento), y segundo, haber obtenido puntuaciones elevadas en sintomatología depresiva (Inventario de Depresión de Beck, BDI >10), ansiosa (Inventario de Ansiedad Estado-Rasgo, STAI-E >30), u obsesiva (Inventario Maudsley de Obsesión-Compulsión, MOCI >14). Una vez aplicado el procedimiento de inducción de estado de ánimo triste, solo se contabilizaron los resultados obtenidos en el experimento de inducción de aquellos sujetos en los que el procedimiento había resultado eficaz: es decir, aquellos en los que el estado de ánimo había cambiado en al menos 1 punto en la dirección esperada (tristeza).

Tras la verificación de todos estos criterios en las dos primeras fases de la investigación experimental, la muestra inicial quedó reducida a 62 sujetos $(23,40$ $\pm 5,11$ años; 91,9 \% mujeres). La composición final de los cuatro grupos experimentales fue: grupo 1 de no inducción de EA y no supresión, 16 sujetos; grupo 2 de no inducción de EA y supresión, 15 personas; grupo 3 de inducción de EA y no supresión, 16 sujetos; grupo 4 de inducción de EA triste y supresión, 15 participantes.

\section{Medidas e Instrumentos}

a) Selección de la imagen-objetivo para el experimento de supresión. La tarea de supresión de imágenes congruentes con un EA triste exigía la selección previa de una imagen que reuniera, como mínimo, tres características: ser valorada como triste, que tuviera connotaciones desagradables y negativas, y que fuera fácil de recordar, ya que un mejor recuerdo facilitaría considerarla como un análogo de una imagen intrusa. Con este fin se presentaron cuatro fotografías en blanco y negro a un grupo de 67 estudiantes de psicología del penúltimo curso de la Licenciatura (edad: $21 \pm 1,34$ años; $88 \%$ mujeres), que representaban a niños en situaciones de guerra y desamparo extremos. Los evaluadores tenían que valorar cada una de las fotografías en tres escalas análogo visuales de 10 puntos ( 0 = nada; 10 = muchísimo): nivel de desagrado que provoca la escena, grado de tristeza que evoca o sugiere, y facilidad para recordarla. Al cabo de una hora, se repitió el mismo proceso. El análisis de resultados indicó que una de estas fotografías era la que había obtenido las valoraciones más extremas en los dos pases, mostrando además la mayor estabilidad entre ambos momentos, por lo que se escogió como imagen-objetivo para ser utilizada posteriormente en el experimento de supresión. Se trata de una fotografía, muy conocida, que muestra a una niña, desnuda y con los brazos abiertos, que huye corriendo junto con otros niños de un bombardeo con napalm en la guerra de Vietnam.

b) Cuestionarios estandarizados: Se utilizaron los tres siguientes: Inventario de Depresión de Beck (BDI; Beck, Rush, Shaw y Emery, 1979). Cuestionario de Ansiedad Estado (Anxiety Inventory State, STAI-E; Spielberger, Gorsuch, Lushene, Vagg y Jacobs, 1983; Seisdedos, 1988).). Inventario de Obsesiones y Compulsiones de Maudsley (Maudsley Obsessive Compulsive Inventory, MOCI; Hodgson y Rachman, 1977). Inventario de 
supresión del Oso Blanco (White Bear Suppression Inventory, WBSI; Muris, Merckelbach y Horselenberg, 1996; Wegner y Zanakos, 1994).

\section{c) Protocolo experimental:}

Registro de frecuencia de ocurrencias de la imagen. Se midió en tres ocasiones en cada uno de los grupos (períodos 1, 2, y 3), por medio de marcas en una cuartilla en blanco.

Escalas análogo visuales (EAV): A lo largo del experimento se tomaron 4 medidas diseñadas expresamente para este estudio. Todas estas variables fueron evaluadas con EAVs de $10 \mathrm{~cm}$. sin números, únicamente 10 marcas.

- Estado de ánimo en ese momento. Esta medida se tomó en $\mathbf{4}$ ocasiones en los grupos de no inducción y en 5 en los de inducción: tras escribir su nombre (pre-inducción), tras la inducción de estado de ánimo (post-inducción), y tras cada uno de los períodos experimentales $(1,2 \mathrm{y}$ 3).

- Esfuerzo de supresión. Tras el período 2 , únicamente en los grupos de supresión

- Éxito de la supresión. En los grupos de supresión, tras el período 2 .

- Molestia causada por el pensamiento-objetivo. Después de los períodos 2 y 3 , a los sujetos de los grupos de supresión.

- Evaluación de las estrategias empleadas para no pensar en la fotografía en el período de supresión. La cumplimentaron solo los sujetos de los grupos de supresión. Se ha adaptado para este estudio a partir de una modificación de las estrategias de la segunda parte del Revised Obsessional Intrusions Inventory (Belloch, Morillo, Luce- ro, Cabedo y Carrió, 2004; Morillo, Giménez, Belloch, Lucero, Carrió y Cabedo, 2003; Purdon y Clark, 1993, 1994). Consta de 7 estrategias que el sujeto debe valorar de 1 a 5 en función del grado en que las haya utilizado $(1=$ «no la he utilizado», a 5 "la he utilizado continuamente»).

\section{Procedimiento}

Los 90 participantes iniciales cumplimentaron un dossier de evaluación con los cuestionarios, precedidos de una pequeña entrevista en la que se recababan datos demográficos e historia reciente de trastornos mentales y/o de tratamientos. Una vez corregido se eliminaron 10 sujetos que presentaban puntuaciones elevadas en BDI, STAI, o MOCI, tal y como se indicó antes. Los restantes 80 participantes fueron citados para realizar el experimento en una segunda sesión de una duración aproximada de $\mathbf{4 0}$ minutos. Se distribuyeron aleatoriamente en grupos de 6 personas. En cada sesión experimental todos los sujetos de cada grupo se asignaron a una misma condición experimental. El procedimiento general se encuentra resumido en la Figura 1.

El experimento se desarrolló en una habitación silenciosa, bien iluminada, pero sin ventanas, con los sujetos separados entre sí mediante una estructura de paneles blancos de $57 \times 72 \mathrm{~cm}$., de manera que se crearon seis "cabinas" individuales. En cada una de ellas se encontraba: el protocolo de evaluación correspondiente al grupo experimental de que se tratase, la fotografía-objetivo boca abajo, un rotulador rojo, un magnetófono con auriculares y una cinta que contenía todas las instrucciones grabadas. Todas las instrucciones fueron grabadas por la misma persona, una mujer adulta, con voz clara pero monótona. 
La tarea experimental constaba de tres partes durante las que los sujetos no debían quitarse los auriculares. La primera fue una introducción común a todos los sujetos; la segunda parte la inducción de estado de ánimo (grupos 3 y 4) o la tarea distractora (grupos 1 y 2); y la tercera, el experimento de supresión, que fue común a todos los grupos. A continuación se describen resumidamente estas partes:

Primera: "Estás participando en un estudio sobre procesos cognitivos. (...) prestes atención y te concentres en las instrucciones (...) de esta grabación. El material que necesitarás está en la mesa. (...) escribe tu nombre en la primera página del cuadernillo». Se dejaron 15 segundos y se continuó «(..), vamos a empezar (...) Marca el cuadro que mejor represente tu estado de ánimo en este momento».

Segunda parte: Inducción de estado de ánimo negativo. El procedimiento de inducción, basado en Baños, Sanchís y Belloch (1995), consistió en la introducción de la pieza de música «Adaggio for Strings» de S. Barber, y la lectura de diez frases auto-referentes con contenido negativo, modificadas de Velten (1968). Los grupos de no inducción (grupos 1 y 2) recibieron la siguiente instrucción: "estás en una condición experimental que consiste en que durante los próximos 9 minutos no tienes que hacer la tarea de otras condiciones experimentales. (...) puedes no hacer nada, o distraerte con los pasatiempos que tienes en el sobre (...)». A los 9 minutos se aviso: «ya han pasado los 9 minutos, deja los pasatiempos a un lado. Pasa de página. Marca el cuadro que mejor represente tu estado de ánimo en este momento". Tras 15 segundos se pidió que pasaran de página, quedando delante una página en blanco.
Tercera parte: experimento de supresión. En los grupos de inducción de estado de ánimo negativo (grupos 3 y 4) la música no dejó de sonar, aunque atenuada. El experimento de supresión, basado en los trabajos de Belloch et al. $(2002,2004)$, constó de cuatro partes. En la primera se introdujo el estímulo visual a suprimir, tras lo cual los sujetos registraron (en 3 periodos de 5 minutos) las re-apariciones o intrusiones de la fotografía. El periodo 1 fue de línea base, y como en nuestros trabajos anteriores, optamos por el empleo de una condición de no expresión, o de «think anything», consistente en mencionar el pensamiento objetivo sin pedir que se exprese (Purdon y Clark, 1999). En el período 2 (registro) los grupos 2 y 4 (de supresión) recibieron instrucciones de suprimir la imagen mientras seguían registrando la frecuencia de ocurrencias, y los de no supresión (grupos 1 y 3) recibieron las mismas instrucciones que en el periodo uno. En el periodo 3, volvieron a registrar la imagen cada vez que les vino a la cabeza, recibiendo instrucciones semejantes a las de la línea base. Tras cada periodo de registro de la aparición la imagen, se evaluó el estado de ánimo. Además, tras el periodo 2 se evaluaron: molestia, éxito de supresión y esfuerzo; y tras el período 3: molestia y estrategias empleadas para la supresión.

\section{RESULTADOS}

\section{Análisis preliminares}

La distribución de hombres y mujeres en los cuatro grupos experimentales fue semejante $\left(\chi^{2}=3,83, p \leq 0,28\right)$. Los grupos eran asimismo equivalentes en edad, y en la totalidad de las variables de cuestionario evaluadas (BDI, STAI-E, MOCI, WBSI). 
Tabla 1. Diferencias entre el estado de ánimo pre- y post-inducción

\begin{tabular}{|c|c|c|c|c|c|c|}
\hline \multirow[b]{2}{*}{$\begin{array}{l}\text { Estado de } \\
\text { Ánimo }\end{array}$} & \multicolumn{2}{|c|}{$\begin{array}{c}\text { No inducción } \\
\text { de Estado de Animo }\end{array}$} & \multicolumn{2}{|c|}{$\begin{array}{l}\text { Inducción } \\
\text { de tristeza }\end{array}$} & \multirow[b]{2}{*}{$F$} & \multirow[b]{2}{*}{$\eta^{2}$} \\
\hline & $\begin{array}{l}\text { Grupo } 1 \\
(n=16)\end{array}$ & $\begin{array}{l}\text { Grupo } 2 \\
(\mathrm{n}=15)\end{array}$ & $\begin{array}{l}\text { Grupo } 3 \\
(\mathrm{n}=16)\end{array}$ & $\begin{array}{l}\text { Grupo } 4 \\
(n=15)\end{array}$ & & \\
\hline Pre-inducción & $2,44(1,26)$ & $2,93(2,21)$ & $2,19(1,16)$ & $2,47(1,45)$ & 0,60 & - \\
\hline Post-inducción & $2,44(1,31)$ & $2,60(1,84)$ & $\mathbf{4 , 3 8}(1,93)$ & $4,73(1,98)$ & $6,84^{\mathrm{a}}$ & 0,26 \\
\hline
\end{tabular}

Nota: Los datos están expresados como: Media (DT); ${ }^{a} p<0,01$.

Efectos de la manipulación experimental: ¿ha sido efectivo el procedimiento de inducción?

El EA de los cuatro grupos antes de comenzar el experimento era equivalente $(F=0,60, p \geq 0,05)$. Sin embargo, cuando se sometió a los participantes de los grupos 3 y 4 al procedimiento de inducción de EA triste, se produjo un cambio significativo en la dirección esperada: es decir, el EA de estos sujetos se tornó significativamente más triste (grupo $3: t=$ 6,$59 ; p<0,0001$; grupo $4: t=5,55 ; p<$ $0,0001)$. En consecuencia, las diferencias en esta variable entre los cuatro grupos fueron asimismo significativas después de la inducción $(F=6,84 ; p \leq 0,001)$, si bien el tamaño del efecto de estas diferencias solo fue moderado $\left(\eta^{2}=0,26\right)$, como cabía esperar en una muestra de personas sanas.

Las comparaciones post-hoc (Tukey) indicaron que, después de la inducción de EA, los dos grupos en los que se había introducido este cambio no diferían entre sí en su EA (grupos 3 y 4), pero sí que mantenian diferencias con los otros dos grupos en los que no se había manipulado el EA ( 1 y 2). En la Tabla 1 se exponen estos resultados, así como los estadísticos utilizados para su cálculo. En consecuencia, podemos concluir que el procedimiento empleado para producir un cambio de EA hacia la tristeza fue eficaz, lo que a su vez indica que los dos grupos de participantes que debían comenzar el experimento de supresión con un EA significativamente más triste que los otros dos grupos, en efecto lo presentaban.

\section{Efecto de la supresión sobre la tasa de imágenes}

En la Tabla 2 se muestran las puntuaciones medias y desviaciones típicas obtenidas por los cuatro grupos experimentales en cada uno de los tres periodos de registro (número de intrusiones de la imagen), así como las diferencias intragrupos en los 3 periodos experimentales

Tabla 2. Recurrencias de la imagen-objetivo en cada periodo de registro

\begin{tabular}{lcclcc}
\hline Grupos & Periodo 1 & Periodo 2 & Periodo 3 & F intra & $\eta^{2}$ \\
\hline 1 - (NI, NS) & $12,69(8,5)^{\mathrm{a}}$ & $10,44(10,4)^{\mathrm{a}}$ & $9,19(9,1)^{\mathrm{a}}$ & 3,56 & 0,19 \\
2 - (NI, SP) & $17,53(10)^{\mathrm{a}}$ & $8,07(4,7)^{\mathrm{b}}$ & $\mathbf{8 , 6 0}(6,1)^{\mathrm{b}}$ & $20,15 *$ & 0,59 \\
3 - (IEA, NS) & $13,31(7,8)^{\mathrm{a}}$ & $8,75(8,48)^{\mathrm{b}}$ & $\mathbf{5 , 1 1}(4,2)^{\mathrm{b}}$ & $11,12^{* *}$ & 0,43 \\
4 - (IEA, SP) & $12,47(10)^{\mathrm{a}}$ & $8,67(12,5)^{\mathrm{ab}}$ & $8,07(9,7)^{\mathrm{b}}$ & $7,52^{*}$ & 0,35 \\
F entre grupos & 1,04 & 0,18 & 0,86 & & \\
\hline
\end{tabular}

Nota: Los datos están expresados como: Media (DT). " $p<0,05 ; "$ " $p<0,001$. Los superíndices a,b,c indican las diferencias intra grupo (Bonferroni), a lo largo de los periodos experimentales. $\mathrm{NI}=\mathrm{Sin}$ inducción de EA triste; IEA=Inducción de EA triste; $N S=$ Sin instrucción de suprimir; $S P=$ Con instrucción de suprimir recurrencias de la imagen). 
(última columna) y las diferencias entregrupos para cada uno de tales períodos (última fila). Respecto a esta última comparación, no encontramos diferencias significativas entre los grupos para cada periodo. Es decir, el número de veces que aparece la imagen en cada grupo a lo largo de los tres periodos, fue equivalente.

Para dar respuesta global a los distintos objetivos de este trabajo respecto a la frecuencia de las intrusiones, se realizó un ANOVA mixto (medidas repetidas) 2 (inducción vs. no inducción, variable entre-sujetos) $x 2$ (supresión vs. no supresión, variable entre-sujetos) $\times 3$ (periodos, variable intra-sujetos) que reveló efectos principales significativos para la frecuencia de intrusiones de la imagen-objetivo a lo largo de los periodos $(F=38,38$; $p=0,0001$ ), con un tamaño del efecto mediano $\left(\eta^{2}=0,398\right)$, así como efectos de interacción entre el periodo en que se evalúa la frecuencia, y las condiciones supresión vs. no supresión, e inducción vs. no inducción $(F=5,44, p=0,05)$ que solo explican un $8,6 \%$ de la varianza. No se encontraron interacciones significativas de primer orden entre la frecuencia a lo largo de los tres periodos temporales y la variable experimental supresión vs. no supresión $(F=2,45, p \geq 0,05)$, ni entre la primera y la variable experimental inducción vs. no inducción $(F=0,85, p \geq 0,05)$. Además, ninguna de las variables experimentales entre sujetos mostró efectos significativos, es decir, no se dieron efectos principales de la condición supresión vs. no supresión $(F=0,097, p \geq 0,05)$, ni de la variable inducción vs. no inducción ( $F$ $=0,67, p \geq 0,05)$ ni de la interacción entre ambas $(F=0,99, p \geq 0,05)$.

Respecto a la interacción de segundo orden, que explica un $8,6 \%$ de la varianza, realizamos un ANOVA mixto agrupando los datos en función de la variable inducción vs. no inducción para averiguar cómo se relacionaban las tres variables, y pudimos observar que en los gru- pos con inducción de EA negativo (grupos 3 y 4), la interacción entre la frecuencia a lo largo de los periodos y la variable supresión vs. no supresión, no era significativa $(F=1,68, p \geq 0,05)$, mientras que esta interacción sí resultó significativa en los grupos de no inducción $(F=6,26, p=0,003)$. Un análisis de esta interacción reveló que la interacción se producía entre los periodos 1 y 2 ( $p=$ 0,0001 ), y no entre el 2 y 3 como era de esperar (véase Figura 2)

Una vez realizado este análisis global, y con el fin de dar respuesta a los objetivos específicos planteados, responderemos a cada uno de ellos por separado, resultados que en realidad se corresponden con los análisis post-hoc del ANOVA que se acaba de comentar.

¿El EA triste provoca un aumento de las recurrencias de una imagen visual afectivamente congruentes con ese EA?

Comparamos las medias de los grupos de inducción con las de los grupos de no inducción para cada periodo, no obteniendo diferencias significativas en ninguno de los periodos $\left(t_{1^{\circ}}=-0,92 ; t_{2^{0}}=\right.$ 0,12 y $\left.t_{3^{\mathrm{g}}}=-0,24 ; p \geq 0,05\right)$. Por tanto podemos decir que el EA triste inducido no provocó un aumento en la frecuencia de los pensamientos intrusos en ninguno de los periodos.

El EA triste ¿induce aumentos paradójicos (aumento inmediato y aumento demorado) en las re-apariciones de una imagen visual afectivamente congruente con el EA como consecuencia de los intentos activos de suprimir esa imagen?

Para responder a esta segunda pregunta, realizamos un ANOVA de medidas repetidas 2 (grupo 2 vs. grupo 4) $\times 3$ (periodos), que reveló efectos principales significativos de la frecuencia $(F=27,29$, $p=0,0001, \eta^{2}=0,49$ ) y de la interacción 


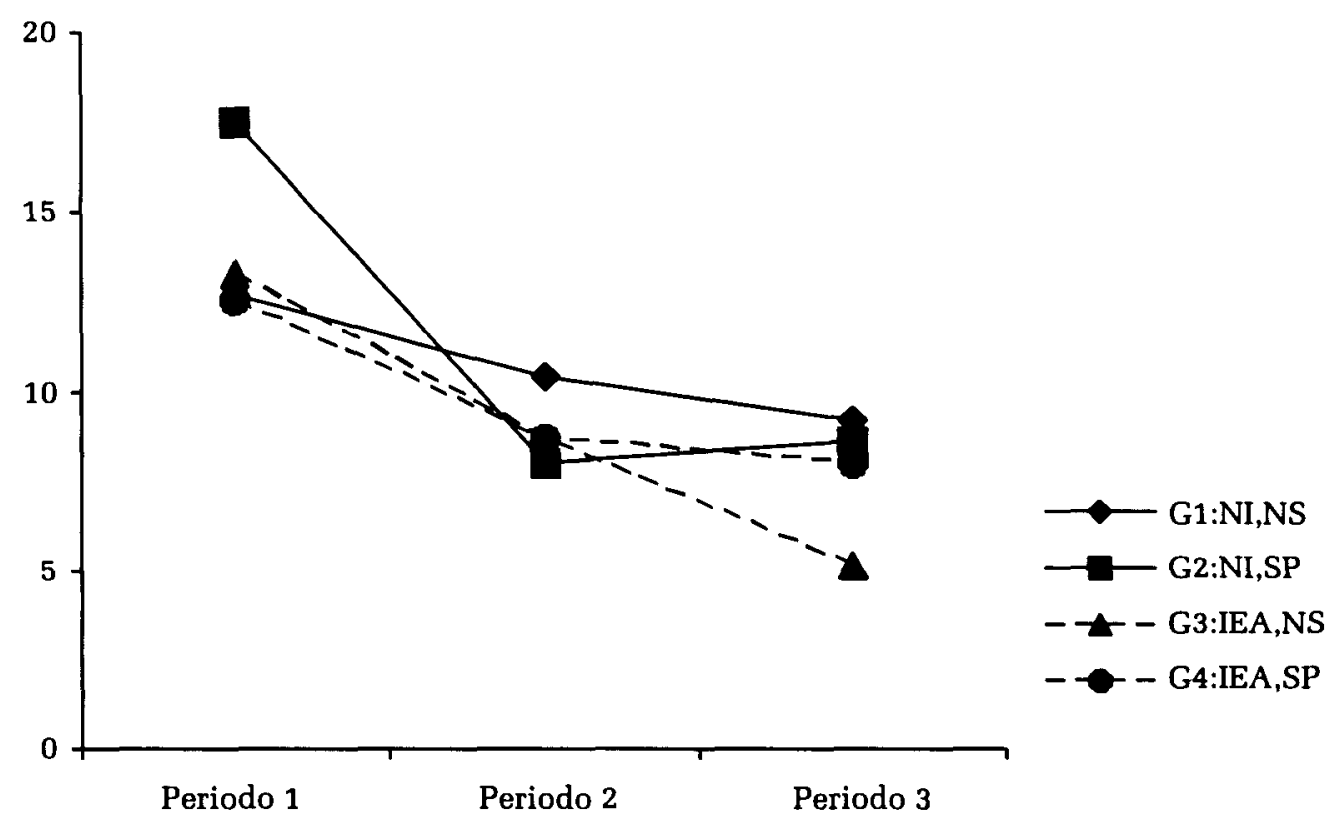

Figura 2. Evolución de la frecuencia a lo largo de los periodos de registro en cada uno de los grupos.

Nota: El Periodo 1 constituye la línea base (registro de recurrencias de la imagen); el Período 2 permite la constatación de efectos de incremento inmediato de la imagen en los dos grupos de supresión por comparación con sus respectivos grupos control y el Período 3 permite constatar la existencia de efecto de incremento demorado (efecto rebote). $\mathrm{G} 1=$ grupo $1 ; \mathrm{G} 2=$ grupo $2 ; \mathrm{G} 3=$ grupo 3; G4 = grupo 4. NI = Sin inducción de EA triste; IEA = Inducción de EA triste; NS = Sin instrucción de suprimir; $\mathrm{SP}=$ Con instrucción de suprimir recurrencias de la imagen.

$\left(F=4,16, p=0,021, \eta^{2}=0,13\right)$, pero no de la inducción $(F=0,28, p \geq 0,05)$. Este último dato ya nos permite responder con una negativa a la segunda de las preguntas. De todos modos analizamos las comparaciones a posteriori, que revelaron que las diferencias se dieron entre los periodos 1 y $2(p=0,0001)$ y 1 y $3(p=$ 0,0001 ). Por tanto, y dada la disminución en la frecuencia desde el periodo de línea base hasta el dos, y la ausencia de diferencias entre los periodos 2 y 3 , podemos concluir que no se produjeron ninguno de los dos aumentos predichos desde el planteamiento de Wegner (1994).

Los sujetos que intentan suprimir activamente una imagen negativa, independientemente de su $E A$, ¿experimentan más efectos paradójicos (aumento inme- diato y aumento demorado) en las reapariciones de una imagen visual negativa, que los sujetos que no intentan suprimirla?

Para responder a esta cuestión realizamos un ANOVA de medidas repetidas 2 (grupos supresión vs. no supresión) $\times 3$ (periodo), que reveló que la supresión (grupos 2 y 4) produjo diferencias en la frecuencia de los periodos $(F=24,6, p=$ $0,0001, \eta^{2}=0,46$ ), concretamente fueron significativas $(p=0,0001)$ las diferencias entre la línea base/periodo $1(15 \pm 10,16)$ y el 2 /supresión $(8,37 \pm 9,3)$, y entre los periodos 1 y 3 /registro $(8,33 \pm 8)$. Se observa pues, que en los grupos de supresión (grupos 2 y 4), ni se produjo un incremento inmediato en la frecuencia de las intrusiones (en realidad se produce 
una disminución), ni un efecto de incremento demorado (se produce un mantenimiento entre los periodos de supresión y registro). Como el objetivo era la comparación entre los grupos de supresión y los de no supresión, realizamos una comparación por pares para cada periodo, revelando la ausencia de diferencias significativas entre los mismos $\left(t_{\text {periodo } 1}=\right.$ 0,$86 ; t_{\text {periodo } 2}=0,59 ; t_{\text {periodo } 3}=-0,517 ; \mathrm{p} \geq$ $0,05)$, por lo que ni se produjeron efectos paradójicos en los grupos de supresión, ni éstos efectos fueron mayores en los grupos de supresión que en los grupos de no supresión.

La evolución de la frecuencia de las intrusiones a lo largo de los periodos en los dos grupos de no supresión (grupos 1 y 3) también fue significativa $(F=13,81$, $\left.p=0,0001, \eta^{2}=0,31\right)$. Las diferencias $(p$ $=0,0001)$ se produjeron entre los periodos $1(13 \pm 8,01)$ y $2(9,59 \pm 9,39)$, y entre el 1 el $3(7,19 \pm 7,27)$. Sin embargo, en estos grupos, a diferencia de los de supresión, se observó una tendencia hacia una disminución progresiva en la frecuencia de intrusiones, en lugar de hacia su mantenimiento. No obstante esta tendencia no fue estadísticamente significativa.

El EA triste ¿se asocia a una disminución del esfuerzo para suprimir, a un menor éxito subjetivo, y a un aumento de la molestia que originan las recurrencias de imágenes afectivamente congruentes con dicho estado?

Cuando analizamos el esfuerzo que, subjetivamente, los sujetos dijeron haber empleado en suprimir de forma activa las recurrencias de la imagen (grupos 2 y 4), los resultados indicaron que, independientemente de que se hallaran bajo un EA triste o normal (Esfuerzo Grupo 4: 5,80 $\pm 2,36$; Esfuerzo Grupo 2: 7,33 \pm $1,95)$, ese esfuerzo había sido similar

$(t=-1,97 ; p=0,058)$. No obstante, como se puede observar por estos resul- tados, los sujetos con EA normal (Grupo 2) indicaron que se habían esforzado más por suprimir reapariciones de la imagen que los que mantenían un EA triste (Grupo 4). Por tanto, la respuesta a la primera parte de la pregunta que se deduce de nuestros resultados es que, en efecto, los sujetos con EA no manipulado se esforzaron más que aquellos a los que se había inducido un EA triste, si bien esta diferencia es escasamente significativa en términos estadísticos.

No hubo diferencias en la molestia subjetiva que les causaba la recurrencia de la imagen-objetivo $(t=-0,97 ; p \geq 0,05)$, ni en el éxito que desde su punto de vista habían logrado en sus esfuerzos por suprimir la imagen (éxito subjetivo de la supresión: $t=0,77 ; p \geq 0,05)$. Del mismo modo, tampoco constatamos diferencias en la molestia que produjo la recurrencia de la imagen en el tercer periodo de registro ("piensa lo que quieras») ( $F=$ 0,$54 ; p \geq 0,05$ ).

A nivel intra-grupo, sí que se observaron diferencias significativas entre la molestia evaluada en el periodo 2 (tras la instrucción de suprimir) y la del periodo 3 (tras la instrucción de "piensa lo que quieras»), tanto en el grupo $2(F=27,09$, $p \leq 0,0001)$ como en el $4(F=7,48, p \leq$ 0,01 ). En el grupo 4 (inducción, supresión) la molestia que producía que viniera la imagen a la mente en el periodo 2 , correlacionó $\left(r^{2}=0,50, p \leq 0,057\right)$ con el esfuerzo realizado para evitar tenerla. Respecto al éxito subjetivo en la supresión, correlacionó de forma negativa con la molestia producida por la recurrencia de la imagen en el periodo $2\left(r^{2}=-0,52, p\right.$ $\leq 0,04)$. Así mismo, el EA tras la supresión (2.9 periodo de registro) correlacionó con la molestia $\left(r^{2}=081, p \leq 0,0001\right)$, y de forma negativa con el éxito subjetivo de la supresión $\left(r^{2}=-0,53, p \leq 0,04\right)$, de tal forma que a mayor éxito percibido, el EA era menos triste. De estas asociaciones, en el grupo 2, solo resultó significa- 
tiva la que relaciona de forma negativa el EA tras el periodo 2 con el éxito subjetivo $\left(r^{2}=-0,62, p \leq 0,01\right)$.

¿Los sujetos cuyo EA triste ha sido inducido, emplean estrategias diferentes para suprimir recurrencias no deseadas de una imagen visual congruente con su EA?

Este apartado hace referencia a los grupos 2 y 4, ya que fue en ellos en los que se pedía a los sujetos que suprimieran en uno de sus periodos de registro (el $2 .^{\mathrm{P}}$ ). Entre estos grupos no se encontraron diferencias significativas en las estrategias de supresión empleadas, por lo que el EA inducido triste no parece influir en la selección de estrategias diferentes. En el grupo 2 (no inducción, supresión) la estrategia de distracción cognitiva: «pensar en otra cosa» correlacionó de forma negativa $\left(r^{2}=-0,644, p \leq 0,013\right)$ con la frecuencia de reapariciones de la imagen en el segundo periodo de registro. $Y$ en el grupo 4, la estrategia de «auto-tranquilización", correlacionó de forma positiva $\left(r^{2}=0,713, p \leq 0,004\right)$ con la frecuencia en el periodo 2 .

No se encontraron correlaciones entre el WBSI y el malestar producido por las intrusiones de la imagen, ni entre este cuestionario y la frecuencia de intrusiones, en contra de lo encontrado por Muris et al. (1996).

\section{Resultados no esperados}

A lo largo de esta investigación hemos detectado un conjunto de resultados que, aun no estando directamente relacionados con las hipótesis y objetivos centrales, fueron lo bastante interesantes como para sugerir una exploración más profunda de los mismos.

Analizamos la evolución del EA en cada grupo a lo largo del experimento, pues nos interesaba conocer los posibles cambios en el EA tras cada una de las fases experimentales, especialmente con el objetivo de comprobar si, tal y como Beevers y Scott (2001) hipotetizan, el EA mejora tras la supresión de imágenes negativas (periodo 2 de los grupos 2 y 4). Para estudiar esta evolución a lo largo de las cinco evaluaciones realizadas (preinducción, post-inducción, tras $1 .^{9}$ periodo de registro/linea base, tras el $2 .^{\circ}$ periodo de registro/supresión vs. no supresión, y tras el $3 .^{\circ}$ periodo de registro), realizamos un ANOVA mixto de medidas repetidas ( $2 \times 2 \times 4)$. Los resultados se muestran en la Tabla 3 .

Se constató la existencia de un efecto principal del EA a lo largo de sus mediciones $\left(F=27,79, p=0,0001, \eta^{2}=\right.$ 0,325 ), indicando por lo tanto cambios a lo largo del procedimiento experimental. Sin embargo, no hubo interacción entre el EA y la condición «suprime vs. no suprimas» $(F=0,54, p \geq 0,05)$, ni

Tabla 3. Valoraciones del EA a lo largo del procedimiento experimental en los cuatro grupos

\begin{tabular}{lcccccc}
\hline \multirow{2}{*}{ Grupo } & \multicolumn{2}{c}{ Inducción Estado Animo } & \multicolumn{3}{c}{ Experimento Supresión } & \multirow{2}{*}{ F intra } \\
\cline { 2 - 6 } & EA pre-Ind. & EA post-Ind. & EA periodo 1 & EA periodo 2 & EA periodo 3 & \\
\hline 1: NI,NS & $2,44(1,26)$ & $2,44(1,31)$ & $3,81(1,05)$ & $3,63(1,26)$ & $3,63(1,1)$ & $13,51^{\mathrm{b}}$ \\
2: NI,SP & $2,93(2,22)$ & $2,60(1,84)$ & $4,67(2,25)$ & $4,13(1,81)$ & $3,71(2,30)$ & $5^{\mathrm{a}} 59^{\mathrm{a}}$ \\
3: IEA,NS & $2,19(1,16)$ & $4,38(1,92)$ & $4,13(2,03)$ & $3,56(2,03)$ & $3,19(1,76)$ & $32,26^{\mathrm{c}}$ \\
4: IEA,SP & $2,47(1,45)$ & $4,73(1,98)$ & $4,60(2,13)$ & $4,47(2,03)$ & $3,73(1,98)$ & $4,59^{\circ}$ \\
F entre & 0,60 & $6,84^{\mathrm{c}}$ & 0,69 & 0,87 & 0,63 & \\
\hline
\end{tabular}

Nota: Los datos están expresados como: Media (DT). $" p \leq 0,05,{ }^{b} p \leq 0,01,{ }^{c} p \leq 0,001$

$\mathrm{NI}=$ Sin inducción de estado de ánimo; IEA = Inducción de estado de ánimo triste; NS = Sin instrucción de suprimir; SP = Con instrucción de suprimir recurrencias de la imagen. 
entre el EA, la inducción y la supresión $(F=0,37, p \geq 0,05)$, pero sí fue significativa la interacción de primer orden entre el EA y la variable experimental inducción vs. no inducción, aunque con un tamaño del efecto pequeño $(F=12,94 ; p$ $=0,0001 ; \eta^{2}=0,182$ ). Concretamente, las diferencias entre las distintas mediciones de EA se produjeron, según la corrección de Bonferroni entre el EA pre-inducción y el resto de las mediciones de EA ( $p \leq 0,0001)$, así como entre el EA post-inducción y el EA tras el $1 .^{\circ}$ periodo de registro/línea base $(p \leq 0,01)$. La Figura 3 ejemplifica con claridad esta evolución.
Dado que la el EA variaba en función de la condición inducción de EA vs. no inducción, realizamos otro ANOVA segmentando a los grupos en función de esta condición. Se encontraron efectos principales del EA tanto en el grupo de inducción $\left(F=18,29, p=0,0001, \eta^{2}=\right.$ $0,379)$ como en el de no inducción $(F=$ $7,58, p=0,0001, \eta^{2}=0,336$ ).

En los dos grupos de inducción de EA triste (grupos 3 y 4), la corrección de Bonferroni revelo diferencias entre la primera evaluación del EA (pre-inducción) y el resto de mediciones (post-inducción, línea base del experimento de supresión, periodo 2 del experimento de

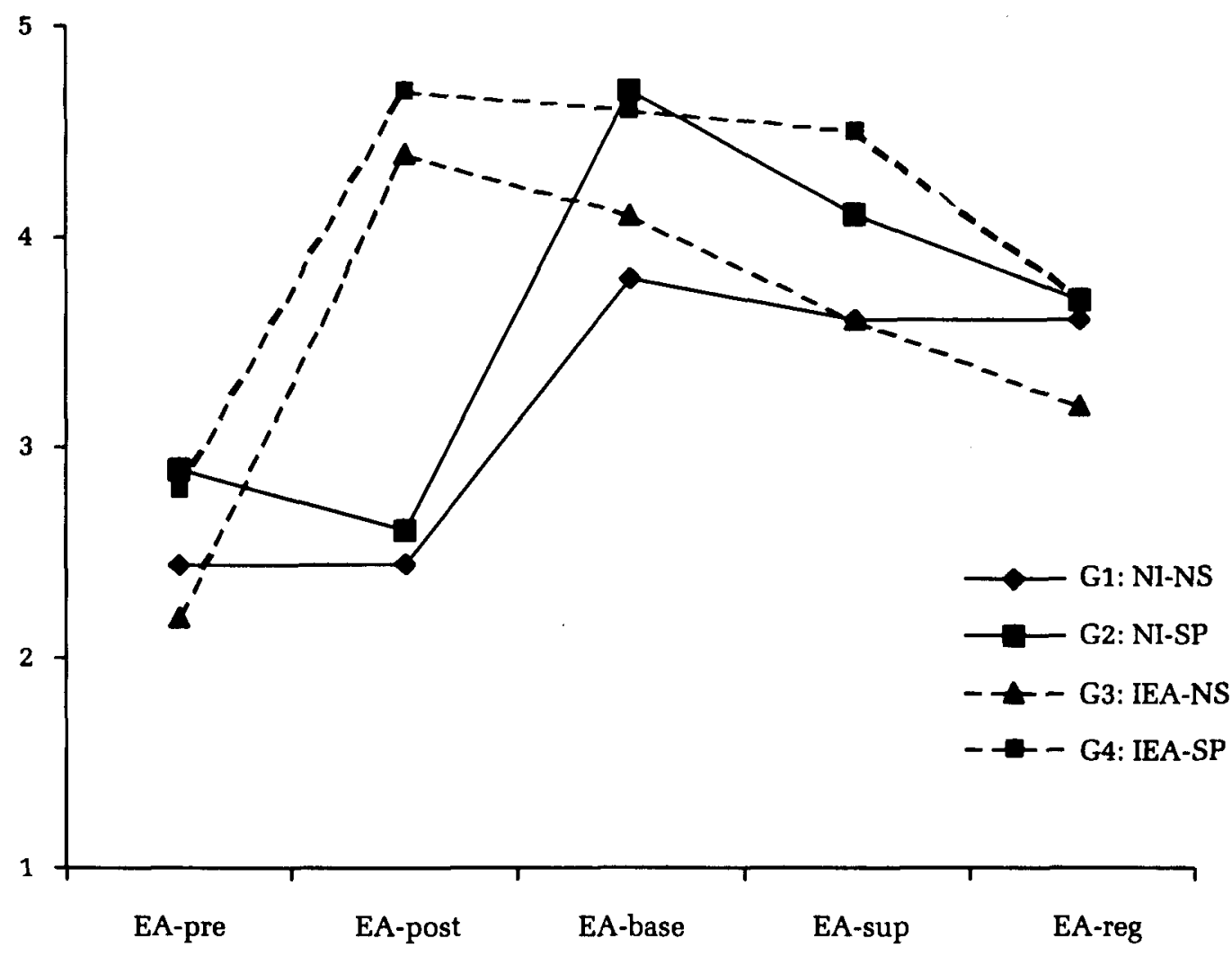

Figura 3. Evolución del EA en cada uno de los grupos (1=nada triste, y 10=muy triste).

Nota: EA-pre: Estado de ánimo antes de la inducción; EA-post: Estado de ánimo luego de inducción; EA-base: Estado de ánimo en el período 1 de línea base; EA-sup: Estado de ánimo en el período 2, de supresión; EA-reg: Estado de ánimo en el periodo 3, de registro post-supresión. $\mathrm{G1}=$ grupo 1; G2 = grupo 2; G3 = grupo 3; G4 = grupo 4. $\mathrm{NI}=$ Sin inducción de EA triste; IEA = Inducción de EA triste; NS = Sin instrucción de suprimir; $\mathrm{SP}=$ Con instrucción de suprimir recurrencias de la imagen. 
supresión, y periodo 3 del experimento de supresión o fase de registro) ( $p \leq$ $0,0001)$, así como entre este último periodo de registro y el resto de mediciones ( $p$ $\leq 0,05$ ). Estos datos indican que los sujetos mantuvieron su EA triste durante todo el experimento de supresión, independientemente de si habían recibido o no instrucciones de suprimir la imagen (grupos 4 y 3 respectivamente), pero en el último periodo (cuando solo tenían que registrar las ocurrencias de la imagen) su EA experimentó una leve mejoría en comparación con los dos periodos anteriores, si bien no alcanzó su nivel normal inicial.

Respecto a los grupos en los que no hubo manipulación del EA (Grupos 1 y 2), las diferencias por pares fueron significativas entre la primera medida del experimento de supresión (línea basesopa de letras), y el EA inmediatamente posterior a la contemplación de la fotografía (periodo 1: $p \leq 0,05$ ), y el subsiguiente al periodo 2 (en el que el Grupo 2 tenía instrucción de suprimir la imagen, y el Grupo 1 simplemente debía registrar sus ocurrencias: $p \leq 0,05$ ).

Estos resultados indican que todos los sujetos comenzaron el experimento de supresión con un EA significativamente más triste del que presentaban al inicio de todo el proceso experimental: en el caso de los sujetos de los grupos 3 y 4 , porque el experimento de inducción de EA triste fue efectivo; y en el caso de los sujetos de los grupos 1 y 2, porque la visión de la imagen-objetivo provocó en sí misma un EA triste. En las posteriores mediciones de EA, éste se mantuvo igual (p.ej., triste) en los cuatro grupos.

\section{DISCUSIÓN}

El objetivo que ha guiado la realización de este trabajo ha sido dilucidar qué influencias podía ejercer un estado de ánimo negativo sobre la eficacia de los esfuerzos deliberados, esto es, voluntarios y conscientes, por suprimir imágenes cuyos contenidos fueran congruentes con dicho estado de ánimo. La comprensión de estas influencias es de gran interés para el TOC, por ser un trastorno mental caracterizado por los esfuerzos deliberados por suprimir las propias imágenes, pensamientos o impulsos intrusos, y que a menudo cursa con un trastorno del estado de ánimo comórbido.

La elección de emplear una imagen valorada como negativa (García, 2004, Estudio 1) y común a todos los sujetos, en lugar de un PI personalmente significativo, molesto y relativamente frecuente, como en otros trabajos (p.ej., Belloch et al., 2003, 2004; Purdon y Clark, 2001), estuvo motivada por un triple interés: minimizar el peso de los contenidos autorreferentes; estudiar el patrón de supresión de imágenes negativas, consideradas funcionalmente equivalentes a los pensamientos o ideas negativas en la definición del TOC (véase por ejemplo, el DSM-IV-TR), y porque desde que Wegner empleó la supresión de «un oso blanco» (que obviamente refiere más a una imagen que a un pensamiento), la mayoría de investigaciones publicadas han comparado una imagen neutra ("oso blanco») con pensamientos (personalmente relevantes o no). Por tanto, emplear una imagen, nos permitía comprobar si tal y como argumentan Belloch et al. (2004), los resultados e inconsistencias halladas en la literatura sobre supresión se deben a los esfuerzos previos por suprimir, o más bien a lo que el sujeto tiene que suprimir, es decir, al estímulo empleado.

Respecto a los resultados, los análisis preliminares realizados sobre los datos demográficos y sobre los cuestionarios de ansiedad, depresión, sintomatología obsesiva, y tendencia a suprimir, mostraron que los cuatro grupos no diferían en ninguna de estas variables. También veri- 
ficamos que los sujetos comenzaron el experimento con el mismo nivel de tristeza, y que el procedimiento de inducción de EA negativo fue efectivo, pues tras la inducción de EA negativo en los grupos 3 y 4, su EA empeoró, diferenciándose de los grupos que no habían recibido este procedimiento (grupos $1 \mathrm{y}$ 2: tarea distractora). De forma que los sujetos de los grupos inducidos comenzaron el experimento de supresión con un EA más negativo que los grupos de no inducción.

Utilizamos el procedimiento modificado de Velten (frases negativas autorreferentes y música) para la inducción de un estado de ánimo triste porque cuenta con una amplia validación empírica (Baños, Sanchís y Belloch, 1995; Martin, 1990). $Y$, aunque poner a prueba la eficacia del procedimiento de inducción no era el objetivo de este trabajo, no deja de ser llamativo que no ejerciera ningún efecto sobre prácticamente la tercera parte de los sujetos a los que se aplicó (16 de 49), a pesar de que a nivel estadístico sus efectos fueron significativos. Por este motivo eliminamos a aquellos sujetos sobre los que la inducción no había tenido ningún efecto. Dado que una tercera parte de los sujetos señalaron que su EA no empeoró, consideramos que podemos estar razonablemente seguras de que los sujetos fueron sinceros al realizar sus evaluaciones de EA tras la inducción experimental, esto es, no presentaron deseabilidad social, o no se dejaron llevar por las expectativas de la experimentadora.

Respecto al objetivo central de este trabajo, el estudio del patrón de respuesta ante la instrucción de supresión vs. no supresión tanto induciendo EA triste como no induciéndolo, no hemos encontrado diferencias significativas entre los grupos en la frecuencia de las intrusiones a lo largo de los periodos. Por tanto, no se han dado ni efectos paradójicos ni efec- tos rebote en la frecuencia de las imágenes, resultado consistente con los obtenidos por otros autores en población normal (Belloch et al., 2003, 2004; Janeck y Calamari, 1999; Purdon, 2001; Purdon y Clark, 2001) y en población clínica (Purdon, Rowa, y Antony, 2004). Las instrucciones de suprimir han interferido en el declinar natural o habituación a las imágenes, tal y como se ha encontrado en los trabajos que han empleado pensamientos intrusos personalmente significativos (Belloch et al., 2003, 2004; Purdon y Clark, 2001). Este dato resultaría más aclarador, si solo hubiera ocurrido en los grupos de supresión, pero a nivel estadístico, este mantenimiento también se ha observado en los grupos control, aunque si observamos la figura que representa la evolución de la frecuencia de las intrusiones a lo largo de los periodos experimentales (Figura 2) observamos una tendencia en los grupos control a la disminución progresiva de la frecuencia de las intrusiones, mientras que la tendencia observada en los grupos de supresión, es hacia el mantenimiento de las intrusiones. Parece pues que, suprimir tiene un efecto inmediato positivo, pero interfiere en la habituación natural a la imagen y en la disminución progresiva de la frecuencia de las intrusiones. Es posible que estas tendencias pudieran resultar significativas en un estudio con mayor número de sujetos, pero como es natural también podría darse el efecto contrario.

Aunque hemos hallado una interacción de segundo orden que parecía indicar que la evolución temporal de la variable supresión vs. no supresión, variaba en función de la otra condición experimental (la inducción), al analizar detenidamente esta interacción, se observa que es puramente azarosa, y se debe a que uno de los grupos tenía más imágenes intrusas en la línea base que el otro, y en el periodo 2 , durante el que debía supri- 
mir, la frecuencia disminuyó más que la del otro grupo experimental, por lo que las líneas se cruzan y la interacción resulta significativa. Porlo tanto, el estado de ánimo no ejerce una carga mental que influya sobre la supresión de imágenes comunes negativas (Wegner, 1994) parece más bien que, independientemente del EA, el comportamiento ante la supresión de una imagen negativa común ha sido el mismo, y diferente del obtenido ante la supresión de un pensamiento intruso personal.

Por lo que hace referencia a la influencia de las variables experimentales sobre la molestia subjetiva que provocan las intrusiones, evaluada tras el periodo de supresión y tras el tercer periodo de registro, hemos encontrado que la molestia era mayor en el primer caso. Parece pues, que cuando la recurrencia se interpreta como fracaso en la tarea de supresión, o como intrusión, es más molesta que cuando es una simple recurrencia (bajo la condición «piensa lo que quieras»). En el grupo 4 (inducción, supresión) observamos que la molestia se relacionaba de forma positiva con los esfuerzos por suprimirla, de forma negativa con el esfuerzo de evitación, y con el éxito subjetivo. Así mismo, el EA tras la supresión (2. ${ }^{\circ}$ periodo de registro) correlacionó con la molestia, y de forma negativa con el éxito subjetivo de la supresión (relación también significativa en el grupo 2), de tal forma que a mayor éxito percibido, el EA era menos triste. Pero no correlacionó con el EA en el periodo previo de registro, por lo que no podemos señalar que tener un determinado EA influya sobre el éxito percibido. Parece más bien al contrario: el éxito percibido influyó sobre el EA.

Los resultados obtenidos indican que el EA negativo no influyó en la elección de las estrategias de control evaluadas (distracción cognitiva, auto-tranquilización, no hacer nada, revaloración, etc.).
Estos datos van en la línea de los obtenidos por otros autores (Amir et al., 1997; Freeston y Ladouceur, 1997), que señalan que el pobre control de los pensamientos intrusos durante el EA disfórico, no se debe al empleo de estrategias diferentes, sino a que estas son menos efectivas, tal vez debido a la mediación de las valoraciones.

Para el grupo 2, "pensar en otra cosa» durante el periodo de supresión, resultó ser una estrategia efectiva. Por lo tanto, parece que cuando la depresión o la tristeza impiden prestar atención a la imagen, ésta pierde fuerza y se recuerda menos. Si estas suposiciones son correctas, podría decirse que al deprimido, que está focalizando su capacidad atencional consciente en su EA negativo y en sus pensamientos/imágenes autorreferentes, le resulta fácil distraerse de aquellas imágenes o ideas que, aun siendo congruentes con su estado disfórico, no sean autorreferentes. $Y$ en el grupo 4, la «auto-tranquilización» resultó ser inefectiva.

Por último hemos señalado un apartado de resultados no esperados en el que se estudia la evolución del EA a lo largo de todo el experimento. En primer lugar, hay que señalar que el EA no mejoró tras el periodo de supresión (periodo 2 en los grupos 2 y 4), en oposición a lo que hipotetizan Beevers y Scott (2001). Respecto a los grupos de la condición de inducción de EA triste (grupos 3 y 4), el EA empeora tras la misma y mejora ligeramente tras el último periodo de registro; pero en los grupos de no inducción (grupos 1 y 2), el EA no se mantuvo estable respecto a la línea base como habíamos supuesto, sino que empeoró tras ver la fotografía durante 1 minuto, y registrar su frecuencia durante cinco. Resulta llamativo el hecho de que ver la imagen objetivo solo empeorara el EA en los grupos de no inducción, esto sugiere que tal vez haya un efecto techo en la capacidad de 
inducir experimentalmente un EA triste a personas normales, que una vez alcanzado impediría que el EA empeorara. Por este motivo, aunque tras la inducción se les mostró a los grupos 3 y 4 la imagen objetivo (inductora de EA triste en los grupos 1 y 2), el efecto techo evitó que el EA de estos grupos se hiciera más triste.

En definitiva, todos los grupos comenzaron el periodo 2 (supresión vs. no supresión) con un EA equivalente, inducido de forma directa mediante el procedimiento modificado de Velten, o de forma indirecta visualizando una imagen triste. Por tanto, las conclusiones anteriores cabría modificarlas y señalar que independientemente de que el EA triste se haya inducido de modo directo o indirecto, el comportamiento ante la supresión de una imagen negativa común ha sido el mismo, y diferente del obtenido ante la supresión de un pensamiento intruso personalmente significativo. Así mismo, estos resultados vienen a indicar que será el estímulo a suprimir, y no los esfuerzos por suprimir, lo que incide en las dificultades de habituación encontradas por algunos autores (Belloch et al., 2003, 2004; Purdon y Clark, 2001).

Una de las limitaciones de este trabajo, es que no hemos empleado una imagen autorreferente y personalmente significativa como lo son los PI análogos a las obsesiones. No podemos descartar, por tanto, que los resultados obtenidos no sean extrapolables a una situación en la que se haga uso de imágenes auto-referentes, con connotaciones personales. No obstante hemos de señalar que cuando en la definición de una idea obsesiva se alude a este aspecto, se apela a contenidos egodistónicos por su incongruencia con la opinión que se tiene de uno mismo (a diferencia de los pensamientos negativos auto-referentes de los deprimidos, que sí que son congruentes con la propia autoimagen), y en este sentido la imagen que hemos utilizado genera egodistonía por- que es incompatible con los deseos y opiniones de los sujetos.

Otra posible limitación está relacionada con el hecho de que pedíamos a los participantes que suprimieran una imagen no auto-referente pero, a la vez, utilizamos frases con contenidos auto-referentes para inducir un EA triste. Es posible que ello haya ejercido algún papel de confusión en los participantes y, a partir de ahí, haya influido en un sentido difícil de predecir y controlar en los resultados.

El hecho de que la imagen haya inducido EA negativo en los grupos de no inducción, no nos ha permitido comprobar el efecto de la supresión de imágenes negativas con EA no inducidos, por lo que sería interesante que posteriores trabajos replicaran estos resultados empleando una imagen que no sea inductora de EA, o bien mostrando la fotografía y evaluando el EA antes de proceder a la inducción de EA triste, de modo que los efectos sobre el EA de la inducción actúen sobre la posible «inducción» de la fotografía. De todos modos, dado que la supresión vs. no supresión no ha tenido efectos significativos, tal vez fuera más interesante inducir EA en grupos que suprimieran imágenes intrusas personalmente significativas, o al menos más cercanas a los sujetos (p.ej., atentados del 11-M), o pensamientos intrusos.

Posteriores trabajos deberán estudiar la influencia del EA ansioso sobre la efectividad de la supresión. En esta misma línea, ya señaló Tolin, Abramowitz, Przeworski y Foa (2002) la necesidad de investigar si en el TOC era más fácil intentar la supresión de pensamientos bajo condiciones de laboratorio de ansiedad. En definitiva, pensamos que a pesar de sus limitaciones el trabajo que se presenta puede servir de base para avanzar en la investigación de las interrelaciones entre el estado de ánimo y la supresión consciente de pensamientos intrusos. 


\section{REFERENCIAS BIBLIOGRÁFICAS}

Abramowitz, J.S., Tolin, D.F., y Street, G.P. (2001). Paradoxical effects of thought suppression: A meta-analysis of controlled studies. Clinical Psychology Review, 21, 683-703.

Amir, N., Cashman, L., y Foa, E.B. (1997). Strategies of thought control in obsessivecompulsive disorder. Behaviour Research and Therapy, 35, 775-777.

Anderson, J.R., y Bower, G.H. (1973). Human Associative Memory. Washington, DC: Winston.

APA (2002). DSM-IV-TR. Manual diagnóstico y estadístico de los trastornos mentalesTexto revisado. Barcelona: Masson.

Baños, R.M., Sanchís, C., y Belloch, A. (1995). Sesgos de interpretación en los estados emocionales. Análisis y Modificación de Conducta, 21, 23-49.

Beck, A.T., Rush, A.J., Shaw, B.F., y Emery, G. (1979). Cognitive Therapy of Depression. Nueva York: Guilford press (traducción castellana en Bilbao: Desclée de Brower, 1983).

Beevers, C.G., y Scott, W.D. (2001). Ignorance may be bliss, but thought suppression promotes superficial cognitive processing. Journal of Research in Personality, 35, 546553.

Belloch, A. y Morillo, C. (2002). Efectos de la supresión de pensamientos neutros y pensamientos intrusos análogos a las obsesiones en sujetos normales. Revista de Psicopatología y Psicología Clínica, 7, 177-194.

Belloch, A., Morillo, C., y Giménez, A. (2004). Effects of suppressing neutral and obsession-like thoughts in normal subjects: beyond frequency. Behaviour Research and Therapy, 42, 841-857.

Belloch, A., Morillo, C., Lucero, M., Cabedo, E., y Carrio, C. (2004). Intrusive thoughts in non-clinical subjects: the role of frequency and unpleasantness on appraisal ratings and control strategies. Clinical Psychology and Psychotherapy, 11, 100-110.

Blaney, P.H. (1986). Affect and memory: A review. Psychological Bulletin, 99, 229. 246.

Bower, G. H. (1981). Mood and memory. American Psychologist, 36, 129-148.
Clark, D.A. (1992). Depressive, anxious and intrusive thoughts in psychiatric inpatients and out patients. Behaviour Research and Therapy, 30, 93-102.

Clark, D.A., y Purdon, C.L. (1993). New perspectives for a cognitive theory of obsessions. Australian Psychologist, 28, 161167.

Conway, M., Howell, A., y Giannopoulos, C. (1991). Dysphoria and Thought Suppression. Cognitive Therapy and Research, 15, 153-167

Edwards, S., y Dickerson, M. (1987). On the similarity of positive and negative intrusions. Behaviour Research and Therapy, 25, 207-211.

Freeston M.H., Rhéaume, J., y Ladouceur, R. (1996). Correcting faulty appraisals of obsessional thoughts. Behaviour Research and Therapy, 34, 433-446.

Freeston, M., Ladouceur, R., Thibodeau, N., y Gagnon, F. (1992). Cognitive intrusions in a non-clinical population. II. Associations with depressive, anxious, and compulsive symptom. Behaviour Research and Therapy, 30, 263-271.

Freeston, M., y Ladouceur, R. (1997). What do patients do with their obsessive thoughts? Behaviour Research and Therapy, 35, 335348

García, G. (2004). Influencia del estado de ánimo sobre la supresión de imágenes. Universidad de Valencia: Facultad de Psicología (trabajo de investigación para la obtención de la suficiencia investigadora).

Hodgson, R.J., y Rachman, S. (1977). Obsessional compulsive complaints. Behaviour Research and Therapy, 15, 389-395.

Howell, A., y Conway, M. (1992). Mood and the suppression of positive and negative self-referent thoughts. Cognitive Therapy and Research, 16, 535-555.

Ingram, R.E. (1984). Toward an informationprocessing analysis of depression. Cognitive Therapy and Research, 8, 443-478.

Insem, T.R., Gillin, J.C., Moore, A., Mendelson, W.B., Lavenstein, J.R., y Murphy, D.L. (1982). Sleep in obsessive compulsive disorder. Archives of General Psychiatry, 39, 1372-1377.

Janeck, A.S., y Calamary, J.E (1999). Thought Suppression in Obsessive-Compulsive 
Disorder. Cognitive Therapy and Research, 23, 497-509.

Martin, M. (1990). On the induction of mood. Clinical Psychology Review, 10, 669-697. McNally, R., y Ricciardi, J.N. (1996). Suppression of Negative and neutral thoughts. Behavioural and Cognitive Psychotherapy, 24 17-25.

Morillo, C., Giménez, A., Belloch, A., Lucero, M., Carrió, C., y Cabedo, E. (2003). Pensamientos intrusos en obsesivos subclínicos: contenidos, valoraciones y estrategias de control. Revista de Psicopatología y Psicología Clínica, 8, 23-38.

Muris, P., Merckelbach, H., y Horselenberg, R. (1996). Individual differences in thought suppression. The White Bear Suppression Inventory: Factor structure, reliability, validity and correlates. Behaviour Research and Therapy, 34, 501-513.

Niler, E.R., y Beck, S.J. (1989). The relationship among guilty, anxiety and obsessions in a normal population. Behaviour Research and Therapy, 27, 213-220.

Purdon, C. (1999). Thought suppression and psychopathology. Behaviour Research and Therapy, 37, 1029-1054.

Purdon, C. (2001). Appraisal of obsessional thought recurrences: impact on anxiety and mood state. Behaviour Therapy, 32, 47-64.

Purdon, C. (2004). Empirical investigations of thought suppression in OCD. Journal of Behavior Therapy and Experimental Psychiatry, 35, 121-136.

Purdon, C., y Clark, D.A. (1993). Obsessive intrusive thoughts in non-clinical subjects. Part I. Content and relation with depressive, anxious, and obsessional symptoms. Behaviour Research and Therapy, 31, 713-720.

Purdon, C., y Clark, D.A. (1994). Obsessive Intrusive thoughts in non-clinical subjects. Part II. Cognitive appraisal, emotional response and thought control strategies. Behaviour Research and Therapy, 32, 403-410.

Purdon, C., y Clark, D.A. (1999). Thought suppression and psychopathology (Invited Essay). Behaviour Research and Therapy, 37, 1029-1054

Purdon, C., y Clark, D.A. (2000). White Bears and Other Elusive Intrusions. Behaviour Modification, 24, 425-453
Purdon, C., y Clark, D.A. (2001). Suppression of obsession-like thoughts in nonclinical individuals: impact on thought frequency, appraisal and mood state. Behaviour Research and Therapy, 39, 1163-1181

Purdon, C., Rowa, K., y Antony, M.M. (2004). Thought suppression and its effects on thought frequency, appraisal and mood state in individuals with obsessive-compulsive disorder. Behaviour Research and Therapy (en prensa, on line 5 febrero 2004).

Rachman, S. (1981). Part I. Unwanted intrusive cognitions. Advances in Behaviour Research and Therapy, 3, 89-99.

Rachman, S. (1997). A cognitive theory of obsessions. Behaviour Research and Therapy, 35, 793-802.

Rachman, S. (1998). A cognitive theory of obsessions: elaborations. Behaviour Research and Therapy, 36, 385-401

Rachman, S. (2002). A cognitive theory of compulsive checking. Behaviour Research and Therapy, 40, 625-639

Rassin, E., Merckelbach, H., y Muris, P. (2000). Paradoxical and less paradoxical effects of thought suppression: a critical review. Clinical Psychology Review, 20, 973-995.

Reynolds, M., y Salkovskis, P.M. (1991). The relationship among guilt, dysphoria, anxiety and obsessions in a normal population: an attempted replication. Behaviour Research and Therapy, 30, 259-265.

Rutledge, P.C. (1998). Obsessionality and the attempted suppression of unpleasant personal intrusive thoughts. Behaviour Research and Therapy, 36, 403-416.

Salkovskis, P.M., y Westbrook, D. (1989). Behaviour therapy and obsessional rumiations. Can failure be turned into success? Behaviour Research and Therapy, 27, 149-160.

Salkovskis, P.M. (1985). Obsessional-compulsive problems: a cognitive-behavioural analysis. Behaviour Research and Therapy, 23, 571-583.

Salkovskis, P.M. (1989). Cognitive-behavioural factors and the persistence of intrusive thoughts in obsessional problems. Behaviour Research and Therapy, 27, 677-682.

Salkovskis, P.M. (1996). Cognitive-behavioural approaches to the understanding of obsessional problems. En R.M. Rapee (Ed.), 
Current controversies in the anxiety disorders. Nueva York: Guilford Press.

Salkovskis, P.M,. y Campbell, P. (1994). Thought Suppression induces intrusion in naturally occurring negative intrusive thoughts. Behaviour Research and Therapy, 32, 1-8.

Seisdedos, N. (1988). Cuestionario de Ansiedad Estado-Rasgo. Adaptación Española. Madrid: TEA.

Spielberg, C.D., Gorsuch, R.L., Lushene, R.E., Vagg, P.R., y Jacobs, G.A. (1983). Manual for the State-Trait Anxiety Inventory (form Y). Palo Alto, California: Consulting Psychologist Press.

Sutherland, G., Newman, B., y Rachman, S. (1982) Experimental investigations of the relations between mood and intrusive unwanted cognitions. British Journal of Medical Psychology, 55, 127-138.

Teaslade, J.D., y Russell, M.L. (1983). Differential effects of induced mood on the recall of positive, negative and neutral words. British Journal of Clinical Psychology, 22, 163-172.

Tolin, D.F., Abramowitz, J.S., Przeworski, A., y Foa, E.B. (2002). Thought suppression in obsessive-compulsive disorder. Behaviour Research and Therapy, 40, 1255-1274.

Trinder, H., y Salkovskis, P.M. (1994). Personally Relevant Intrusions Outside the laboratory: long-term suppression increases intrusion. Behaviour Research and Therapy, 32, 833-842
Velten, E. (1968). A laboratory task for induction of mood states. Behaviour Research and Therapy, 6, 473-482.

Wegner, D.M. (1994). Ironic processes of mental control. Psychological Review, 101, 34-52.

Wegner, D.M., y Erber, R. (1992). The hypperaccesibility of suppressed thoughts. Journal of Personality and Social Psychology, 63, 903-912.

Wegner, D.M., y Zanakos, S. (1994). Chronic thought suppression. Journal of Personality and Social Psychology, 62, 615-640.

Wegner, D.M., Schneider, D.J., Carter, S.R., y White, T.L. (1987). Paradoxical effects of thought suppression. Journal of Personality and Social Psychology, 53, 5-13.

Wenzlaff, R.M., Wegner, D.M., y Roper, D.W. (1988). Depression and mental control: the resurgence of unwanted thoughts. Journal of Personality and Social Psychology, 55, 882-892.

Wenzlaff, R.M., Wegner, D.M., y Klein, S.B. (1991). The role of thought suppression in the bonding of thought and mood. Journal of Personality and Social Psychology, 60, 500-508.

Yaryura-Tobías, J., Todazo, J., Grunes, M.S., McKay, D., Stockman, R., y Nexiroglu, F.A. (1996). Comorbidity versus continuum of axis I disorders in $O C D$. Comunicación presentada en el Congreso de la Asociación para el Avance de la Terapia de Conducta, Nueva York. 